\title{
Adubação de potássio em cobertura nos componentes de produção de cultivares de girassol ${ }^{1}$
}

\author{
Potassium fertilization in sidedressing in the yield components of sunflower cultivars
}

\author{
Sandra Cátia Pereira Uchôa ${ }^{2 *}$, Maria Elena de Almeida Ivanoff ${ }^{3}$, José Maria Arcanjo Alves ${ }^{4}$, Tocio Sediyama ${ }^{5}$ e \\ Stéfanny Araújo Martins ${ }^{6}$
}

\begin{abstract}
Resumo - O potássio é um nutriente que afeta positivamente a produção de aquênios na cultura do girassol (Helianthus annuus L.) e o seu manejo adequado torna-se indispensável para o melhor aproveitamento desse elemento e menor impacto ambiental. A exigência nutricional entre cultivares da mesma espécie é distinta, mesmo sob condições semelhantes de cultivo. Objetivando avaliar os componentes de produção de três cultivares de girassol submetidas a diferentes doses de cobertura de potássio, foi realizado um experimento em Latossolo Amarelo distrocoeso na savana de Roraima. O delineamento estatístico foi o de blocos casualizados em esquema fatorial ( 3 x 5), com quatro repetições. Os tratamentos consistiram da combinação de três variedades (Agrobel 960, Agrobel 967 e Embrapa 122/V2000) e cinco doses de potássio em cobertura (0;30; 60;90 e $120 \mathrm{~kg} \mathrm{ha}^{-1}$ ). Os efeitos das doses de $\mathrm{K}$ foram independentes dos efeitos das cultivares. O híbrido Agrobel 967 apresentou superioridade na produtividade de aquênios, produtividade de óleo e no teor de óleo em relação ao híbrido Agrobel 960 e a variedade Embrapa 122/V2000. A dose mais econômica de potássio em cobertura para produtividade de aquênio e produtividade de óleo foi de 74,5 e 80,1 $\mathrm{kg} \mathrm{ha}^{-1}$, respectivamente. As produções máximas alcançadas pela adição de doses crescentes de $\mathrm{K}_{2} \mathrm{O}$ em cobertura foram de $2.038,3 \mathrm{~kg} \mathrm{ha}^{-1}$ de aquênios, com 52,5\% de óleo na semente e 1.079,3 $\mathrm{kg} \mathrm{ha}^{-1}$ de rendimento de óleo.
\end{abstract}

Palavras-chave - Helianthus annuus L.. Produtividade de aquênio. Teor de óleo. Savana de Roraima.

\begin{abstract}
Potassium is a nutrient that positively affects achenes production within sunflower crop (Helianthus annuus L.) and its proper management is indispensable for better economical employment of this element and for a less environmental impact. Requirement nutritional between cultivars of the same species is distinct, even under the same conditions of cultivation. In order to assess production components of three sunflower cultivars submitted to different rates of potassium sidedressing an experiment was conducted in distrocohesive Yellow Latosol in the savanna of Roraima, in randomized blocks and factorial schema ( $3 \times 5$ ), with four replicates. Treatments consisted of the combination of three varieties (Agrobel 960, Agrobel 967 and Embrapa 122/V2000) and five rates of potassium side dressing $\left(0 ; 30 ; 60 ; 90\right.$ and $\left.120 \mathrm{~kg} \mathrm{ha}^{-1}\right)$. Effects of rates of $\mathrm{K}$ were independent from the effects of the cultivars. Hybrid Agrobel 967 presented superiority in productivity of of achenes, oil and oil content in relation to the hybrid Agrobel 960 and to the variety Embrapa 122/V2000. The most economic rate of potassium in sidedressing for productivity of achene and productivity oil was 74.5 and $80.1 \mathrm{~kg} \mathrm{ha}^{-1}$, respectively. The maximum productions achieved by adding increasing rates of $\mathrm{K}_{2} \mathrm{O}$ as sidedressing were $2,038.3 \mathrm{~kg} \mathrm{ha}^{-1}$ of achenes, with $52.5 \%$ of oil in seed and $1,079.3 \mathrm{~kg} \mathrm{ha}^{-1}$ of oil yield.
\end{abstract}

Key words - Helianthus annuus L.. Achene yield. Oil teor. Savannah of Roraima.

\footnotetext{
* Autor para correspondência

${ }^{1}$ Recebido para publicação em 04/06/2010; aprovado 10/11/2010

Parte da dissertação de Mestrado do segundo autor, apresentada ao Programa de Pós-Graduação em Agronomia/POSAGRO, CCA/UFRR ${ }^{2}$ Departamento de Solos e Engenharia Agrícola/CCA-UFRR, BR 174, Km 12, s/n, Campus do Cauame, Boa Vista-RR, Brasil, 69.310-270, scpuchoa@dsi.ufrr.br

${ }^{3}$ Bolsista do CNPq, programa de Pós-Graduação em Agronomia com área de concentração em Produção Vegetal, Universidade Federal de Roraima, Boa Vista- RR, Brasil, 69.310-270, lena ivanoff@hotmail.com

${ }^{4}$ Departamento de Fitotecnia/CCA-UFRR, BR 174, Km 12, s/n, Campus do Cauame, Boa Vista-RR, Brasil, 69.310-270, arcanjoalves@dft.ufrr.br ${ }_{5}^{5}$ Departamento de Fitotecnia, UFV, Av. PH Rolfs, Campus Universitário, Viçosa-MG, Brasil, 36.570-000, t.sediyama@ufv.br

${ }^{6}$ Bolsista do PIBIC/CNPq, graduando do Curso de Agronomia Universidade Federal de Roraima, Boa Vista- RR, Brasil, 69.310-270, stefanny.

martins@bol.com.br
} 


\section{Introdução}

A cultura do girassol, Helianthus annuus L., possui um dos maiores índices de crescimento no mundo. Em 2006 foram plantados 23 milhões de hectares, produzindo cerca de 32 milhões de toneladas de sementes (FAO, 2008). No Brasil a área plantada com girassol, em 2006, foi de 69.206 hectares, com rendimento médio de $1.475 \mathrm{~kg} \mathrm{ha}^{-1}$. Na safra de 2008/2009 houve um incremento para 75.000 hectares (CONAB, 2010). Essa cultura vem crescendo devido à busca por novas opções de cultivo, ao aumento da demanda das indústrias por óleo de melhor qualidade e também para produção de biocombustíveis. Na Amazônia, o girassol pode ser incluído no sistema de produção das pequenas propriedades por fornecer o óleo e outros produtos de alto valor agregado, tais como: a casca e a torta, com 45 a $50 \%$ de proteína bruta.

O cultivo do girassol deve ser feito em solos que não apresentem restrições físicas e químicas, sendo a sua exigência em relação ao teor de potássio superior as culturas do milho e da soja. O incremento na produtividade agrícola, decorrente da adição dos fertilizantes potássicos ao solo, varia principalmente com a quantidade de $\mathrm{K}$ disponível e com o nível geral da fertilidade do solo. De acordo com Sfredo et al. (1984), o girassol extrai 40\% mais $\mathrm{K}$ do que as culturas da soja e do milho. Dados de Castro e Farias (2005) demonstraram que o girassol apresenta teores de $10 \mathrm{~g} \mathrm{~kg}^{-1}$ de $\mathrm{K}$ nas sementes e de $132 \mathrm{~g} \mathrm{~kg}^{-1}$ de $\mathrm{K}$ na palha dos restos culturais, exportando apenas $7 \%$ do potássio acumulado.

O teor de potássio disponível no solo para atender o requerimento da planta deve ser superior a $0,25 \mathrm{cmol}_{\mathrm{c}} \mathrm{dm}^{-3}$ (BLAMEY et al., 1987). Boukert et al. (1997) relatam que menos de $0,12 \mathrm{cmol}_{\mathrm{c}} \mathrm{dm}^{-3}$ de $\mathrm{K}$ disponível mantém baixa a sua absorção, assim como o seu teor na folha, limitando o rendimento produtivo. Concentrações de $\mathrm{K}$ nas folhas superiores a 24,9 $\mathrm{g} \mathrm{kg}^{-1}$ está associada com produtividade acima de aproximadamente $2.000 \mathrm{~kg} \mathrm{ha}^{-1}$. Quanto ao nível crítico de potássio no solo, Villalba (2008) cultivando girassol em dois solos com $60 \%$ e $20 \%$ de argila, obteve valores de 0,41 e $0,23 \mathrm{cmol}_{\mathrm{c}} \mathrm{dm}^{-3}$, respectivamente, demonstrando a variação do nível crítico de $\mathrm{K}$ em função do teor de argila do solo.

O modo de aplicação dos fertilizantes potássicos ao solo depende do teor de $\mathrm{K}$ disponível, da textura do solo, da espécie vegetal e da quantidade a ser aplicada. Em algumas situações a adubação potássica deve ser parcelada em duas vezes, e isso ocorre para solos arenosos, de baixa CTC, ou quando a dose a ser aplicada na semeadura é muito alta, independentemente da CTC. A adição de doses muito altas de $\mathrm{K}_{2} \mathrm{O}$ por ocasião da semeadura, superiores à faixa de 80 a $100 \mathrm{~kg} \mathrm{ha}^{-1}$, pode prejudicar a germinação e, ou, o crescimento inicial da planta em razão do aumento excessivo na concentração salina próximo das sementes. Para os solos do cerrado, a dose máxima sugerida para ser adicionada por ocasião da semeadura sem riscos de prejuízo à emergência é de $60 \mathrm{~kg} \mathrm{ha}^{-1}$ de $\mathrm{K}_{2} \mathrm{O}$ (VILELA et al., 2004).

A obtenção de informações por meio da pesquisa tem sido decisiva para dar suporte tecnológico ao desenvolvimento da cultura do girassol, garantindo melhores produtividades e retornos econômicos competitivos. Entre as várias tecnologias a escolha adequada de cultivares constitui um dos principais componentes do sistema de produção da cultura. Diante da existência de interação genótipo $\mathrm{x}$ ambiente são necessárias avaliações continuadas, em redes de ensaios, a fim de determinar o comportamento agronômico dos genótipos e sua adaptação às diferentes condições locais (DE LA VEJA; CHAPMAN, 2006; LU'QUEZ, 2002; PORTO et al., 2007; PORTO et al., 2008).

A necessidade de gerar mais informações científicas acerca da produção de girassol motivou a elaboração deste estudo. Objetivou-se, portanto, avaliar o efeitos de doses de cobertura de potássio em algumas características agronômicas e nos componentes de produção de três cultivares de girassol, nas condições de savana de Boa Vista, em Roraima.

\section{Material e métodos}

O experimento foi conduzido durante os meses de janeiro a maio de 2008 , em área de savana (cerrado) do Centro de Ciências Agrárias da Universidade Federal de Roraima (CCA/UFRR), no município de Boa Vista, Estado de Roraima - Brasil. As coordenadas geográficas são $2^{\circ} 52^{\prime} 15,49^{\prime \prime}$ ' $\mathrm{N}$ de latitude, $60^{\circ} 42^{\prime} 39,89^{\prime}$ ' W de longitude e $90 \mathrm{~m}$ de altitude. O clima da região é do tipo Awi, de acordo com a classificação de Köppen, com duas estações climáticas bem definidas: uma chuvosa (abril-setembro) e outra seca (outubro-março) (ARAÚJO et al., 2001). A precipitação média anual é de $1.678 \mathrm{~mm}$, umidade relativa do ar de $70 \%$ e a temperatura varia de 20 a $38^{\circ} \mathrm{C}$, sendo a média anual de $27,4{ }^{\circ} \mathrm{C}$.

O solo da área do experimento é classificado em Latossolo Amarelo distrocoeso, e apresentava as seguintes características na camada de 0 a $20 \mathrm{~cm}: \mathrm{pH}\left(\mathrm{em} \mathrm{H}_{2} \mathrm{O}\right)=6,1$; Al trocável $\left(\mathrm{cmol}_{\mathrm{c}} \mathrm{dm}^{-3}\right)=0,0 ; \mathrm{Ca}+\mathrm{Mg}\left(\mathrm{cmol}_{\mathrm{c}} \mathrm{dm}^{-3}\right)=2,33$; P- Mehlich $1\left(\mathrm{mg} \mathrm{dm}^{-3}\right)=12,3 ; \mathrm{K}\left(\mathrm{mg} \mathrm{dm}^{-3}\right)=39,1$; Matéria orgânica $=10,6 \mathrm{~g} \mathrm{dm}^{-3} ; \mathrm{V}(\%)=65,6 ; \mathrm{m}(\%)=0,0 ;$ Soma de bases $=2,43\left(\mathrm{cmol} \mathrm{dm}^{-3}\right) ; \mathrm{CTCt}=3,55\left(\mathrm{cmol} \mathrm{dm}_{\mathrm{c}}^{-3}\right)$; CTCe $=2,43\left(\mathrm{cmol} \mathrm{dm}_{\mathrm{c}}^{-3}\right)$; argila $=260 \mathrm{~g} \mathrm{~kg}^{-1}$, silte $=159 \mathrm{~g} \mathrm{~kg}^{-1} \mathrm{e}$ areia $=590 \mathrm{~g} \mathrm{~kg}^{-1}$ (EMBRAPA, 1997). 
O delineamento estatístico utilizado foi o de blocos casualizados em esquema fatorial ( $5 \times 3$ ), com quatro repetições. O primeiro fator correspondeu as doses de potássio em cobertura $\left(0 ; 30 ; 60 ; 90\right.$ e $\left.120 \mathrm{~kg} \mathrm{ha}^{-1} \mathrm{~K}_{2} \mathrm{O}\right)$ e o segundo, as cultivares, resultando em 15 tratamentos. A parcela experimental foi constituída por cinco fileiras de 4,0 $\mathrm{m}$ de comprimento com espaçamento entre linhas de $0,70 \mathrm{~m}$ e $0,20 \mathrm{~m}$ entre plantas. Para efeito de coleta de dados foram consideradas as três linhas centrais, eliminando-se $0,5 \mathrm{~m}$ nas extremidades das fileiras, sendo a área útil de $6,3 \mathrm{~m}^{2}$.

Utilizaram-se três cultivares de girassol, selecionadas pelas características específicas de produção de óleo e por serem materiais promissores para o cultivo na região Norte, sendo: C1 - Agrobel 967 (Grão Negro) - híbrido simples, ciclo de 117 dias, resistente ao acamamento, altura de $1,75 \mathrm{~m}$, população indicada de 45.000 a 46.000 plantas ha $^{-1}$ e teor de óleo entre 45 a 55\%; C2 - Agrobel 960 (Grão Negro) - híbrido triplo, ciclo de 90 a 118 dias, resistente ao acamamento, altura de $1,70 \mathrm{~m}$, população indicada de 45.000 plantas ha-1 e teor de óleo entre 42 a 48\%; C3 - Embrapa 122/V2000 (Grão estriado) - variedade, ciclo de 100 dias, altura de $1,55 \mathrm{~m}$, população entre 40.000 a 45.000 plantas ha- ${ }^{-1}$, teor de óleo entre 40 a $44 \%$.

O preparo do solo foi realizado com uma aração profunda $(30-40 \mathrm{~cm})$ seguida de duas gradagens. Foi realizado adubação via foliar utilizando-se $107 \mathrm{~mL} \mathrm{ha}^{-1}$ de boro plus $\left(11,5 \%\right.$ de $B$ ) aplicado na fase $\mathrm{R}_{1}$. Foram semeadas três sementes a cada $0,20 \mathrm{~m}$ de sulco, sendo realizado o desbaste aos 20 dias após a emergência, quando se deixou apenas uma planta, obtendo-se uma população de 71.428,57 plantas ha' ${ }^{-1}$. Ao longo do cultivo foram realizadas três capinas e duas aplicações com inseticida organofosforado visando o controle da vaquinha (Cerotoma arcuatus) (OLIVIER, 1791). A manutenção da umidade do solo foi feita por meio de irrigação por aspersão, monitorada por tensiômetros, mantendo-se as parcelas a $80 \%$ da capacidade de campo.

A adubação de semeadura foi realizada manualmente aplicando-se $500 \mathrm{~kg} \mathrm{ha}^{-1}$ do fertilizante da fórmula 2-24-12 de NPK no sulco de plantio. Foi realizada uma adubação de cobertura com $50 \mathrm{~kg} \mathrm{ha}^{-1}$ de $\mathrm{N}$ na forma de uréia aos 30 dias após a emergência das plantas. A cobertura de $\mathrm{K}_{2} \mathrm{O}$, na forma de cloreto de potássio $(\mathrm{KCl})$, foi aplicada na mesma época do $\mathrm{N}$ e variou de acordo com as doses estudadas $\left(0 ; 30 ; 60 ; 90\right.$ e $\left.120 \mathrm{~kg} \mathrm{ha}^{-1} \mathrm{~K}_{2} \mathrm{O}\right)$. As adubações de coberturas foram realizadas a lanço, na linha de cultivo a $20 \mathrm{~cm}$ do colo da planta.

As variáveis avaliadas foram: altura de planta medida até a inserção do capítulo no florescimento pleno, $\mathrm{R}_{5.5}$; altura do capítulo - medida do nível do solo até a base do capítulo, no início da maturação, $\mathrm{R}_{9}$; diâmetro da haste - medido com paquímetro a $5 \mathrm{~cm}$ do nível do solo em uma amostra de dez plantas da área útil, no final do florescimento pleno; diâmetro do capítulo - medido em dez capítulos amostrados dentro da área útil; teor de $\mathrm{K}$ na folha - medida em uma amostra da matéria seca de 25 folhas colhidas no estádio R1 na área útil de cada parcela; produtividade de aquênios, avaliada na área útil de cada parcela, com a colheita manual dos capítulos, secagem em estufa, trilha mecânica, pesagem e correção da umidade para $11 \%$; teor de óleo - conforme metodologia estabelecida pelo laboratório da Embrapa Soja (Londrina - PR); produtividade de óleo - calculada utilizando-se o teor de óleo dos aquênios (\%) e a produtividade de aquênios, em $\mathrm{kg} \mathrm{ha}^{-1}$.

Os resultados obtidos foram submetidos à análise de variância pelo teste $\mathrm{F}$, a $5 \%$ de probabilidade. $\mathrm{O}$ teste de Tukey, a 5\% de probabilidade, foi utilizado para comparação das médias quando o fator cultivar foi significativo. Realizouse a análise de regressão nos casos de efeito significativo das doses de potássio. A escolha do modelo selecionado para cada variável baseou-se na significância dos parâmetros e nos valores do $\mathrm{R}^{2}$ (ALVAREZ V.; ALVAREZ, 2006). O teste "F" foi utilizado para testar os coeficientes da regressão no mesmo nível de probabilidade. Empregou-se para análise dos dados o programa estatístico SAEG.

A dose de máxima eficiência técnica (MET) de $\mathrm{K}_{2} \mathrm{O}$ em cobertura foi calculada com base na derivada primeira da equação de regressão, igualando-se à zero. A dose de máxima eficiência econômica (MEE) de $\mathrm{K}_{2} \mathrm{O}$ em cobertura foi calculada com base na derivada primeira da equação de regressão, igualando-se à relação entre preços do insumo e do produto, descrito por Oliveira et al. (2007; 2009) e Raij (1991). No entanto, a fim de atenuar os problemas de variação cambial, trabalhou-se com uma relação de troca ao invés de moeda corrente, procurando-se assim dados mais estáveis. Portanto, a "moeda" utilizada nos cálculos, foi o próprio aquênio ou o óleo, considerando-se a seguinte relação de equivalência: $\mathrm{kg}$ de $\mathrm{K}_{2} \mathrm{O}$ por $\mathrm{kg}$ de aquênio e $\mathrm{kg}$ de $\mathrm{K}_{2} \mathrm{O}$ por $\mathrm{L}$ de óleo, sendo a dose mais econômica calculada por meio da relação de $\mathrm{dy} / \mathrm{dx}$ $=\mathrm{a} 1+2 \mathrm{a} 2 \mathrm{x}$. A dose mais econômica ( $\mathrm{x}$ ') foi então calculada por: $x^{\prime}=(\mathrm{a} 1$ - relação de equivalência $) / 2(-\mathrm{a} 2)$.

Os preços adotados foram obtidos da média praticada nos principais Estados produtores em abril de 2008: $\mathrm{R} \$ 2,00 / \mathrm{kg}$ de $\mathrm{K}_{2} \mathrm{O}, \mathrm{R} \$ 0,80 / \mathrm{kg}$ de aquênios e $\mathrm{R} \$$ $3,60 / \mathrm{kg}$ de óleo de girassol. A relação de equivalência foi de 2,5 para aquênios e de 0,55 para o óleo.

\section{Resultados e Discussão}

A interação entre os fatores cultivares e doses de potássio não foi significativa para as variáveis estudadas, 
passando-se a estudar o efeito isolado de cada fator. Exceto o teor de potássio na folha, as demais variáveis foram afetadas de modo significativo pelas cultivares. $\mathrm{O}$ efeito de doses de K só não foi significativo para a variável altura do capítulo (TAB. 1).

A altura das plantas, medida no estágio $\mathrm{R}_{5.5}$, variou de 1,26 m (Embrapa 122/V2000) a 1,35 m (Agrobel 967) (TAB. 2). Esse resultado pode estar associado à precocidade da cultivar Embrapa 122/V2000, o que confere menor período de desenvolvimento das plantas. Os resultados para altura foram inferiores aos obtidos por Smiderle et al. (2005), que variaram de 1,46 a 1,92 m para seis cultivares, no período de janeiro a abril em condições da savana de Roraima. Em condições climáticas do planalto norte catarinense, Backes et al. (2008), encontraram altura de 1,78 m para Embrapa 122/V2000 e de 2,79 m para Agrobel 960. A baixa estatura observada nessas cultivares sugere a possibilidade de seu cultivo em menores espaçamentos ao empregado nesse estudo, contribuindo, com isso, no controle de plantas daninhas (AMABILE et al., 2003).

A cultivar Embrapa 122/V2000 apresentou ciclo de 80 dias, tendo entrado em floração aos $40 \mathrm{DAE}$, quando o ciclo recomendado é de 100 dias e floração aos 53 dias. O híbrido triplo AG-960 tem ciclo estimado entre 90 a 118 dias e o híbrido AG-967 tem ciclo de 117 dias, ambos foram colhidos aos 97 dias. O florescimento precoce e encurtamento do ciclo, para todas as cultivares, podem estar ligados à época de plantio que apresentava elevada intensidade luminosa e alta temperatura. Resultados semelhantes na redução do ciclo foram observados por Smiderle et al. (2005)

A altura do capítulo variou de 89 (Embrapa 122/ V2000) a $96 \mathrm{~cm}$ (Agrobel 967), encontrando-se dentro da faixa necessária à colheita mecanizada (TAB. 2). O diâmetro do capítulo, conforme Tabela 2, variou de 12 a $13 \mathrm{~cm}$ entre as cultivares, superior ao encontrado por

Tabela 1 - Resumo da análise de variância das variáveis agronômicas de três cultivares de girassol, submetidas a diferentes doses de cobertura de potássio em plantio de girassol

\begin{tabular}{lcclcccccc}
\hline \multirow{2}{*}{ F.V. } & \multirow{2}{*}{ G.L } & \multicolumn{8}{c}{ QUADRADO MÉDIO } \\
\cline { 3 - 9 } & & AP & AC & TK & DH & DC & PR & TO & PO \\
\hline BLOCO & 3 & $0,107^{*}$ & $0,023^{*}$ & $0,236^{*}$ & $39,24^{*}$ & $15,19^{*}$ & $1.002 .497,0^{*}$ & $25,66^{*}$ & $349.412,9^{*}$ \\
DK & 4 & $0,031^{*}$ & $0,012^{\text {ns }}$ & $0,246^{*}$ & $18,33^{*}$ & $3,01^{*}$ & $1.736 .011,0^{*}$ & $20,63^{*}$ & $561.065,4^{*}$ \\
CULT & 2 & $0,041^{*}$ & $0,027^{*}$ & $0,011^{\text {ns }}$ & $101,59^{*}$ & $9,05^{*}$ & $1.066 .701,0^{*}$ & $515,86^{*}$ & $819.157,7^{*}$ \\
DK*CULT & 8 & $0,014^{\text {ns }}$ & $0,005^{\text {ns }}$ & $0,010^{\text {ns }}$ & $5,01^{\text {ns }}$ & $0,70^{\text {ns }}$ & $173.613,3^{\text {ns }}$ & $4,04^{\text {ns }}$ & $55.220,70^{\text {ns }}$ \\
Resíduo & 42 & 0,007 & 0,005 & 0,023 & 3,17 & 0,77 & $133.032,9$ & 1,97 & $38.468,38$ \\
\hline \multicolumn{1}{c}{ CV $(\%)$} & & 6,39 & 7,87 & 6,31 & 9,57 & 7,31 & 21,21 & 1,97 & 21,84 \\
\hline
\end{tabular}

FV - Fontes de variação; DK - Doses de K; CULT - Cultivar; AP - Altura da planta (mm); AC - Altura do capítulo (cm); TK - Teor foliar de potássio (\%); DH - Diâmetro da haste (mm); DC - Diâmetro do capítulo (cm); PR - produtividade de aquênio ( $\left.\mathrm{kg} \mathrm{ha}^{-1}\right)$; TO - Teor de óleo (\%); PO - Produtividade de óleo $\left(\mathrm{kg} \mathrm{ha}^{-1}\right){ }^{\text {ns }}$ - não significativo, * - significativo a $5 \%$ de probabilidade pelo teste $\mathrm{F}$

Tabela 2 - Valores médios das variáveis agronômicas de três cultivares de girassol

\begin{tabular}{|c|c|c|c|c|}
\hline \multirow{2}{*}{ Cultivares } & Altura da Planta & Altura do Capítulo & Diâmetro do Capítulo & Diâmetro da Haste \\
\hline & $\mathrm{m}$ & \multicolumn{2}{|c|}{ - } & $\mathrm{mm}$ \\
\hline Agrobel 967 & $1,35 \mathrm{a}$ & $96 \mathrm{a}$ & $12 \mathrm{~b}$ & $20 \mathrm{a}$ \\
\hline Agrobel 960 & $1,30 \mathrm{ab}$ & $90 \mathrm{~b}$ & $12 \mathrm{~b}$ & $20 \mathrm{a}$ \\
\hline \multirow[t]{3}{*}{ Embrapa 122/V2000 } & $1,26 \mathrm{~b}$ & $89 \mathrm{~b}$ & $13 \mathrm{a}$ & $16 \mathrm{~b}$ \\
\hline & Teor de K na folha & Produtividade de aquênios & Produtividade de Óleo & Teor de Óleo \\
\hline & $\mathrm{g} \mathrm{kg}^{-1}$ & \multicolumn{2}{|c|}{--------------------kg ha' ${ }^{-1}$--------------------- } & $\%$ \\
\hline Agrobel 967 & 24,3 & $1.944 \mathrm{a}$ & $1.088 \mathrm{a}$ & $56 \mathrm{a}$ \\
\hline Agrobel 960 & 23,8 & $1.733 \mathrm{ab}$ & $920 \mathrm{~b}$ & $53 \mathrm{~b}$ \\
\hline Embrapa 122/V2000 & 23,9 & $1.482 \mathrm{~b}$ & $685 \mathrm{c}$ & $46 \mathrm{c}$ \\
\hline Média & 24,0 & - & - & - \\
\hline
\end{tabular}

Na coluna, as médias seguidas da mesma letra, não diferem entre si a 5\% de probabilidade pelo teste de Tukey 
Bíscaro et al. (2008), enquanto que o diâmetro de capítulo $(11,9 \mathrm{~cm})$, diâmetro da haste $(18,4 \mathrm{~mm})$ e a produtividade $\left(2.101 \mathrm{~kg} \mathrm{ha}^{-1}\right)$ foram semelhantes aos valores observados para a Agrobel 967 em condições de savana de Roraima. O diâmetro da haste variou de 16 a $20 \mathrm{~mm}$ (Tabela 2), estando de acordo com os observados na literatura (BISCARO et al., 2008; SMIDERLE et al., 2005). A cultivar Embrapa 122/V2000 apresentou os menores resultados para altura da planta, altura do capítulo e diâmetro da haste.

As cultivares apresentaram produtividade de aquênios que variaram de 1.482 a $1.944 \mathrm{~kg} \mathrm{ha}^{-1}$ (TAB. 2). Essa faixa encontra-se entre os valores de 1.447 a $2.619,54 \mathrm{~kg} \mathrm{ha}^{-1}$ obtidos por Porto et al. (2008), que avaliaram o comportamento de cultivares de girassol em ensaio de rede, em três anos agrícolas, para todas as regiões do Brasil. Entretanto, para as condições do Distrito Federal esse valor está aquém dos rendimentos obtidos, que estão acima de $2.500 \mathrm{~kg} \mathrm{ha}^{-1}$ (FARIAS NETO et al., 2000).

Os teores médios de óleo, obtidos pelas cultivares estudadas, encontram-se superiores aos teores de 37 a $41 \%$ observados em seis cultivares de girassol, avaliadas por Smiderle et al. (2005). A produtividade de óleo obtida pelas cultivares Agrobel 960 e Agrobel 967 foi superior as médias obtidas por Porto et al. (2007; 2008) entre 11 cultivares avaliadas quanto à adaptabilidade e estabilidade em diferentes ambientes das Regiões Sul, Sudeste e Nordeste.

O teor de potássio na folha das cultivares não apresentou diferenças com média de $24 \mathrm{~g} \mathrm{~kg}^{-1} \mathrm{deK}$, situandose dentro da faixa considerada adequada (BLAMEY et al., 1987; BORKERT et al., 1997). De acordo com Blamey et al. (1987), teores de $18,0 \mathrm{~g} \mathrm{~kg}^{-1}$ de $\mathrm{K}$ limitam em $50 \%$ o crescimento vegetativo, e produtividades máximas do girassol somente são obtidas com teores maiores que 24,0 $\mathrm{g} \mathrm{kg}^{-1}$ de $\mathrm{K}$ nas folhas maduras e fisiologicamente ativas. Considerando que o teor de potássio não foi limitante é possível que fatores, possivelmente ligados aos aspectos genéticos, passaram a controlar a produção de aquênios pelas cultivares, pois se esperava que as produtividades fossem superiores a $2.000 \mathrm{~kg} \mathrm{ha}^{-1}$, uma vez que Borkert et al. (1997) obtiveram teores de 12,8; 18,8 e 27,0 $\mathrm{g} \mathrm{kg}^{-1}$ de $\mathrm{K}$ na folha e produções de 1.409 ; 2.032 e $1.986 \mathrm{~kg} \mathrm{ha}^{-1}$, respectivamente, demonstrando que, não havendo falta de nutriente essencial como $\mathrm{K}$, o rendimento de girassol pode atingir $2.000 \mathrm{~kg} \mathrm{ha}^{-1}$, ou mais, sendo considerado bom rendimento em uma lavoura.

Para a produtividade média de óleo, teor de óleo e produtividade de aquênios a cultivar Agrobel 967 foi superior em relação às demais cultivares, apresentando rendimento de aquênios de $1.944 \mathrm{~kg} \mathrm{ha}^{-1}$ e relativo de $461 \mathrm{~kg} \mathrm{ha}^{-1}$ de aquênios, 402,9 $\mathrm{kg} \mathrm{ha}^{-1}$ de óleo e 9,94\% de teor de óleo. Portanto, a cultivar Agrobel 967 chegou a produzir $62,97 \%$ a mais de óleo por hectare quando comparada com a cultivar Embrapa 122/V2000, sendo opção promissora para as condições edafoclimáticas do cerrado de Roraima (TAB. 2).

O efeito de doses de potássio sobre as variáveis estudadas foi melhor descrito por um modelo quadrático, excetuando-se o teor de $\mathrm{K}$ na folha que foi descrito por um modelo linear e a altura do capítulo que não foi influenciada pelas doses de potássio (FIG. 1 e 2). O fato do modelo de melhor ajuste, para a maioria das variáveis, ter sido o polinomial quadrático pode ser explicado devido à absorção insuficiente de um elemento que pode ocorrer tanto por sua ausência no meio quanto pela sua indisponibilidade (VIANA et al., 2008).

Na Tabela 3, observa-se que as plantas em função das doses de cobertura de potássio, atingiram a altura máxima de 1,35 m, diâmetro da haste de 19,82 $\mathrm{mm}$ e diâmetro do capítulo de $12,51 \mathrm{~cm}$ na dose de máxima eficiência técnica (MET) de cobertura, situando-se entre 65,6 e 78,6 $\mathrm{kg} \mathrm{ha}^{-1}$ de $\mathrm{K}_{2} \mathrm{O}$. As doses crescentes elevaram a altura da planta, o diâmetro da haste e do capítulo em

Tabela 3 - Equações de altura de planta, diâmetro da haste e diâmetro do capítulo em função das doses de potássio aplicadas em cobertura em plantas de girassol,coeficiente de determinação, dose de máxima técnica (DMET), incremento e eficiência

\begin{tabular}{lccc}
\hline & Altura da Planta $(\mathrm{m})$ & Diâmetro da Haste $(\mathrm{mm})$ & Diâmetro do Capítulo $(\mathrm{cm})$ \\
\hline Equação & $\hat{\mathrm{Y}}=1,22+0,0033 \mathrm{X}-0,00002 * \mathrm{X}^{2}$ & $\hat{\mathrm{Y}}=16,94+0,0878 \mathrm{X}-0,00067 * \mathrm{X}^{2}$ & $\hat{\mathrm{Y}}=11,25+0,0348 \mathrm{X}-0,00024 * \mathrm{X}^{2}$ \\
$\mathrm{R}^{2}$ & 0,96 & 0,92 & 0,96 \\
DMET & 78,6 & 65,6 & 72,5 \\
Variável na DMET & 1,35 & 19,82 & 12,51 \\
Incremento $^{1 /}$ & 0,13 & 2,88 & 1,26 \\
${\text { Eficiência }(\%)^{2 /}}$ & 11 & 17 & 11 \\
\hline
\end{tabular}

${ }^{1 / I n c r e m e n t o ~=~ v a r i a ́ v e l ~ n a ~ d o s e ~ M E T ~-~ v a r i a ́ v e l ~ n a ~ d o s e ~} 0 \mathrm{~kg} \mathrm{ha}^{-1} \mathrm{de} \mathrm{K}_{2} \mathrm{O}$ em cobertura; ${ }^{2 / E f i c i e ̂ n c i a ~}(\%)=\{[($ Variável na dose de MET x 100)/(variável na dose $0 \mathrm{~kg} \mathrm{ha}^{-1} \mathrm{de} \mathrm{K}_{2} \mathrm{O}$ em cobertura)]-100\} 
até $11 \%, 17 \%$ e $11 \%$, respectivamente. Entretanto, os valores alcançados, na dose de MET de K em cobertura, apresentam-se inferiores aos observados na literatura (FARIAS NETO et al., 2000; SMIDERLE et al., 2005).

A altura das plantas também se apresentou inferior a média obtida por Pires et al. (2007), que obtiveram altura máxima de 1,46 $\mathrm{m}$ e produtividade inferior as encontradas neste experimento, portanto apesar da altura média das plantas indicar, de modo geral, o estado nutricional, observa-se que esta é uma variável que somente auxilia na interpretação dos resultados finais de produção de aquênios.

O incremento no diâmetro da haste em função das doses de potássio, constatado na Tabela 3, é importante no girassol, pois reduz o acamamento da cultura e facilita seu manejo, os tratos culturais e a colheita (BISCARO et al., 2008). Em observações de campo não houve acamamento entre as cultivares e doses avaliadas.

A redução da produtividade de aquênios com doses de $\mathrm{K}_{2} \mathrm{O}$ acima daquelas responsáveis pelas máximas produtividades (FIG. 1b) pode indicar que o excesso desse nutriente foi prejudicial ao desenvolvimento do girassol, possivelmente em conseqüência direta do seu efeito antagônico. Aplicações excessivas do adubo podem

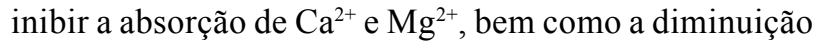
na assimilação do fósforo, chegando, muitas vezes, a causar a deficiência desses nutrientes, implicando, desse modo, em efeitos depressivos sobre a produção das plantas (FORTALEZA et al., 2005). Por outro lado, a deficiência de potássio ocasiona o funcionamento irregular dos estômatos, podendo diminuir a assimilação de $\mathrm{CO}_{2}$, e a taxa fotossintética (CECÍLIO; GRANGEIRO, 2004), afetando negativamente a produção, como é observado no tratamento sem aplicação da dose de K em cobertura. A resposta quadrática das variáveis estudadas sinaliza para um desbalanço catiônico a favor do K no complexo sortivo. Essa hipótese pode ser constatada pela relação linear entre doses de cobertura de $\mathrm{K}$ e o seu teor no tecido foliar (FIG. 1a).

A produtividade de aquênios em função das doses de potássio em cobertura (Figura 1b) apresentou rendimento máximo de $2.038,3 \mathrm{~kg} \mathrm{ha}^{-1}$ de grãos em resposta a uma dose de $83,8 \mathrm{~kg} \mathrm{ha}^{-1}$ de $\mathrm{K}_{2} \mathrm{O}$ (MET), tendo alcançado um incremento na produtividade de $46,4 \%$. Efeito positivo e crescente de doses de potássio $(0 ; 30 ; 60 ; 90 ; 120 ; 150$ e $180 \mathrm{~kg} \mathrm{ha}^{-1}$ ) foi observado na produção e qualidade de sementes de girassol (CAMPOS; SADER, 1987) e em cana-de-açúcar (UCHÔA et al., 2009).

O elevado incremento em produtividade é um indicativo do teor adequado de $\mathrm{K}$ no solo e no tecido foliar pela aplicação da dose de cobertura. A disponibilidade de potássio no solo, para ter produções superiores a $2.000 \mathrm{~kg} \mathrm{ha}^{-1}$, deve ser maior que $0,25 \mathrm{cmol}_{\mathrm{c}} \mathrm{dm}^{-3}$ (BLAMEY et al., 1987). Logo, a cobertura de $83,8 \mathrm{~kg} \mathrm{ha}^{-1}$ de $\mathrm{K}_{2} \mathrm{O}$ somada à adubação de plantio com $60 \mathrm{~kg} \mathrm{ha}^{-1}$ de $\mathrm{K}_{2} \mathrm{O}$, elevou o teor de $\mathrm{K}$ de 0,1 para $0,41 \mathrm{cmol}_{\mathrm{c}} \mathrm{dm}^{-3}$, semelhante ao encontrado por Villalba (2008) para um solo com $60 \%$ de argila.

A dose de máxima eficiência econômica (MEE) foi obtida pela seguinte relação: $[(22,58-2,50) /(2 \times 0,1347)]$, em que 2,50 é a relação entre os preços do insumo e do produto ( $\mathrm{R} \$ 2,00 / \mathrm{R} \$ 0,80)$. Dessa forma, a dose de cobertura mais econômica de $\mathrm{K}_{2} \mathrm{O}$ foi de $74,5 \mathrm{~kg} \mathrm{ha}^{-1}$, com produção de $2.026,7 \mathrm{~kg} \mathrm{ha}^{-1}$ de aquênios, o que representa um incremento de $934,3 \mathrm{~kg} \mathrm{ha}^{-1} \mathrm{em}$ relação ao tratamento sem cobertura. Deduzindo da quantidade de aquênios (186,3 $\mathrm{kg} \mathrm{ha}^{-1}$ ou 3,1 sacas), necessário para aquisição de $74,5 \mathrm{~kg} \mathrm{ha}^{-1}$ de $\mathrm{K}_{2} \mathrm{O}$, resultando um superávit de $1.840,4 \mathrm{~kg}$ $\mathrm{ha}^{-1}$, o que representa um ganho adicional de 30,7 sacas de aquênios. A dose mais econômica apresentou $89 \%$ daquela responsável pela produtividade máxima, o que pode indicar a viabilidade econômica do emprego de cobertura com potássio no cultivo de girassol.
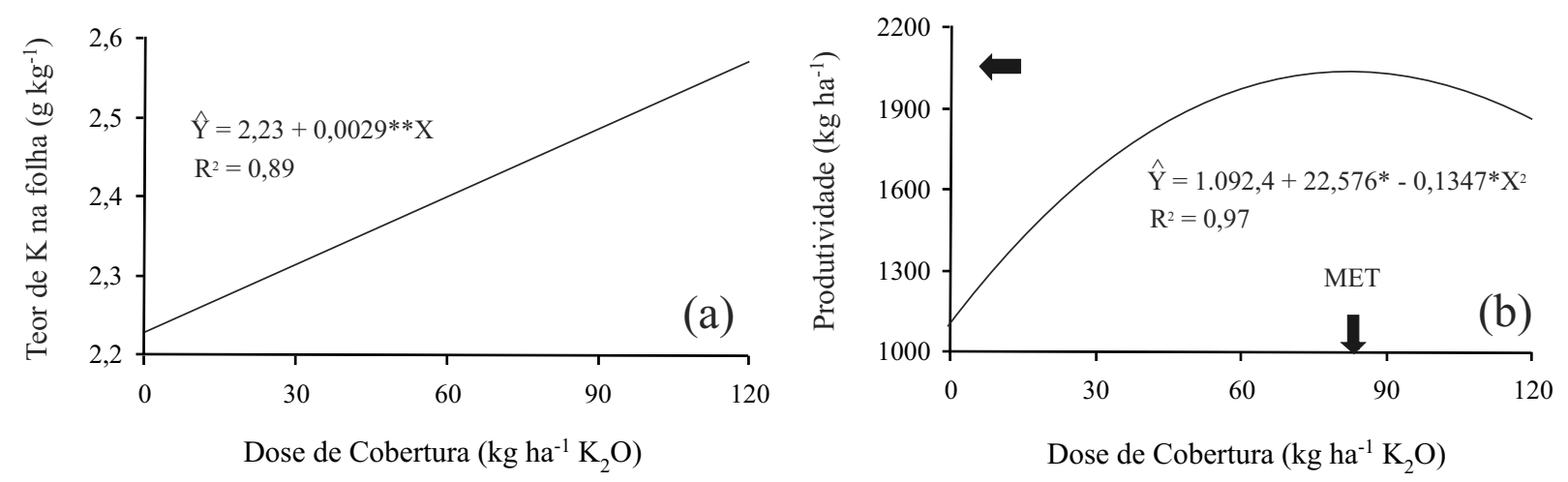

Figura 1 - Teor de potássio na folha (a) e produtividade de aquênios (b) de girassol em função de dose de potássio em cobertura, na savana de Boa Vista, em Roraima, 2008 

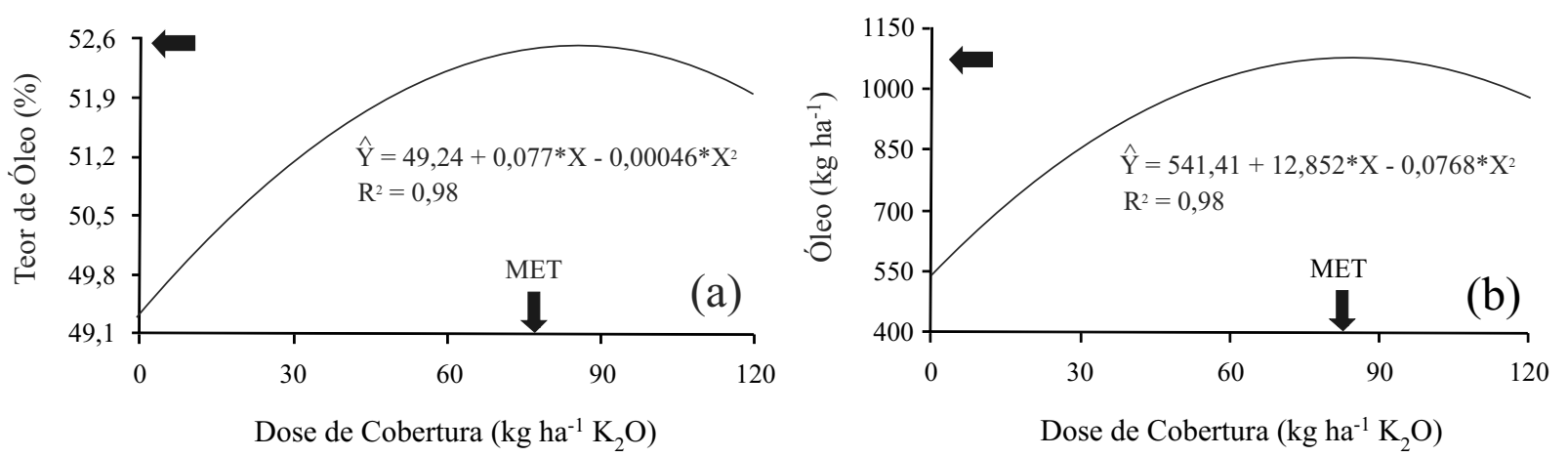

Figura 2 - Teor de óleo de girassol (a) e produtividade de óleo (b) em função das doses de potássio em cobertura na savana de Boa Vista, em Roraima, 2008

O teor de óleo no girassol (Figura 2a) em função de doses de cobertura de potássio indicou que o rendimento máximo (MET) foi de 52,5\% de óleo, na dose de $84,62 \mathrm{~kg} \mathrm{ha}^{-1}$ de $\mathrm{K}_{2} \mathrm{O}$ em cobertura, correspondendo a um incremento de $3,26 \%$. Até a dose de MET as doses de cobertura do potássio proporcionaram aumentos na produtividade de aquênios e no teor de óleo. Os resultados revelam que a adição de $\mathrm{K}$ favorece a produção de óleo na cultura do girassol.

A produtividade de óleo de girassol (Figura $2 b$ ) em função das doses de cobertura de potássio indicou que o rendimento máximo (MET) foi de 1.079,3 $\mathrm{kg} \mathrm{ha}^{-1}$ de óleo, na dose de 85,62 $\mathrm{kg} \mathrm{ha}^{-1}$ de $\mathrm{K}_{2} \mathrm{O}$ em cobertura, o que corresponde a um incremento de $537,86 \mathrm{~kg} \mathrm{ha}^{-1}$ de óleo. A dose de cobertura mais econômica para a produção de óleo foi de $80,1 \mathrm{~kg} \mathrm{ha}^{-1}$ de $\mathrm{K}_{2} \mathrm{O}$, com produção de $1.078,1 \mathrm{~kg} \mathrm{ha}^{-1}$ de óleo, o que representa um incremento de $536,7 \mathrm{~kg} \mathrm{ha}^{-1}$ em relação ao tratamento sem a cobertura. Deduzindo a quantidade de óleo (44,5 $\mathrm{kg} \mathrm{ha}^{-1}$ de óleo), necessário para aquisição de $80,1 \mathrm{~kg} \mathrm{ha}^{-1}$ de $\mathrm{K}_{2} \mathrm{O}$, resultou em um superávit de 1.033,6 $\mathrm{kg} \mathrm{ha}^{-1}$. A dose mais econômica apresentou 93,6\% daquela responsável pela produtividade máxima, o que pode indicar a viabilidade econômica do emprego de cobertura de potássio no cultivo de girassol para a produção de óleo. As doses obtidas para a máxima eficiência física $\left(85,62 \mathrm{~kg} \mathrm{ha}^{-1} \mathrm{de} \mathrm{K}_{2} \mathrm{O}\right)$ e máxima efíciência econômica $\left(80,1 \mathrm{~kg} \mathrm{ha}^{-1}\right.$ de $\left.\mathrm{K}_{2} \mathrm{O}\right)$ são muito próximas devido ao elevado valor agregado do óleo de girassol.

Os resultados para produção de aquênios, teor de óleo e produtividade de óleo demonstram a necessidade da adubação de cobertura com o potássio, além da aplicação da dose recomendada na semeadura $\left(60 \mathrm{~kg} \mathrm{ha}^{-1} \mathrm{~K}_{2} \mathrm{O}\right)$. Considerando o baixo nível de potássio em solos de savana, a aplicação de $60 \mathrm{~kg} \mathrm{ha}^{-1}$ de $\mathrm{K}_{2} \mathrm{O}$ proporcionou entrada de $24,9 \mathrm{mg} \mathrm{dm}^{-3}$ de $\mathrm{K}$ no complexo sortivo. Conforme Castro et al. (1993), a quantidade de potássio considerada crítica para o desenvolvimento normal do girassol é de $78 \mathrm{mg} \mathrm{kg}^{-1}$.
Logo, a adubação em cobertura elevou a concentração de $\mathrm{K}$ para condições superiores ao ponto crítico, propiciando aumentos no rendimento que viabilizam a implantação da cultura em área de savana de Roraima.

\section{Conclusões}

1. O híbrido Agrobel 967 apresentou superioridade em relação ao híbrido Agrobel 960 e a variedade Embrapa 122/V2000, na produtividade de óleo e no teor de óleo;

2. A dose de máxima eficiência econômica para produtividade de aquênio e produtividade de óleo foi de 74,5 e $80,1 \mathrm{~kg} \mathrm{ha}^{-1}$ de $\mathrm{K}_{2} \mathrm{O}$ em cobertura, respectivamente;

3. As produções máximas alcançadas pela adição de doses crescentes de $\mathrm{K}_{2} \mathrm{O}$ foram de $2.038,3 \mathrm{~kg} \mathrm{ha}^{-1}$ de aquênios, $52,5 \%$ de óleo na semente, com produção estimada de óleo de $1.079,3 \mathrm{~kg} \mathrm{ha}^{-1}$.

\section{Referências}

ALVAREZ V., V. H.; ALVAREZ, G. A. M. Comparações de médias ou testes de hipóteses? Contrastes! Boletim Informativo da SBCS, v. 31, p. 24-34, 2006.

AMABILE, R. F.; GUIMARÃES, D. P.; NETO, A. L. F. de. Análise de crescimento de girassol em Latossolo com diferentes níveis de saturação por bases no Cerrado. Revista Pesquisa Agropecuária Brasileira, v. 38, n. 02, p. 219-224, fev. 2003.

Araújo, W. F. et al. Precipitação pluviométrica provável em Boa Vista, Estado de Roraima, Brasil. Revista Brasileira de Engenharia Agrícola e Ambiental, v. 05, n. 03, p. 563-567, 2001.

BACKES, R. L. et al. Desempenho de cultivares de girassol em duas épocas de plantio de safrinha no planalto norte catarinense. Scientia Agraria, v. 09, n. 01, p. 41-48, 2008. 
BISCARO, G. A. et al. Adubação nitrogenada em cobertura no girassol irrigado nas condições de Cassilândia-MS. Ciência e Agrotecnologia, v. 32, n. 05, p. 1366-1373, 2008.

BLAMEY, F. P. C.; EDWARDS, D. G.; ASHER, C. J. Nutritional disorders of sunflower. Brisbane: University of Queensland, 1987.72 p.

BORKERT, C. M. et al. Efeito residual da adubação potássica sobre girassol e milho em três diferentes Latossolos Roxos. Pesquisa Agropecuária Brasileira, v. 32, n. 12, p. 1227- 1234, 1997.

CAMPOS, M. S. O de; SADER, R.; Efeito do potássio na produção e qualidade das sementes de girassol. Revista Brasileira de Sementes, v. 09, n. 03, p. 19-27, 1987.

CASTRO, C. de; FARIAS, J. R. B. Ecofisiologia do girassol. In: LEITE, R. M. V. B. C.; BRIGHENTI, A. M.; CASTRO, C. de. (Ed). Girassol no Brasil. Londrina: Embrapa Soja, 2005. p. 163-210.

CECÍLIO FILHO, A. B.; GRANGEIRO, L. C. Produtividade da cultura da melancia em função de fontes e doses de potássio. Ciência e Agrotecnologia, v. 28, n. 03, p. 561- 569, 2004.

CONAB - Companhia Nacional de Abastecimento. Monitoring of the Brazilian grain harvest in Brazil: Grãos: safra 2009/2010: Quarto levantamento. 2010. 44 p. Disponível em: <http://www. conab.gov.br/conabweb/download/safra/04_levantamento_ jan2010.pdf $>$. Acesso em: 212010.

DE LA VEGA, A. J.; CHAPMAN, S. C. Defining sunflower selection strategies for a highly heterogeneous target population of environments. Crop Science, v. 46, p. 136-144, 2006.

EMPRESA BRASILEIRA DE PESQUISA AGROPECUÁRIA - EMBRAPA. Centro Nacional de Pesquisas de Solos. Manual de métodos de análises de solos. 2. ed. Rio de Janeiro, 1997.

FAO (2008) Disponível em: <http://faostat.fao.orglsitel340/ default.aspx>. Acesso em: 20 jul. 2009.

FARIAS NETO, A. L. de et al. Avaliação de variedades de girassol nos Cerrados do Distrito Federal. Revista Ceres, v. 47, n. 273, p. 469-482, 2000.

FORTALEZA, J. M. et al. Características físicas e químicas em nove genótipos de maracujá-azedo cultivado sob três níveis de adubação potássica. Revista Brasileira de Fruticultura, v. 27, n. 01, p. 124-127, abr., 2005.

LU'QUEZ, J. E. et al. Stability and adaptability of cultivars in non-balanced yield trials. Comparison of methods for selecting 'high oleic' sunflower hybrids for grain yield and quality. Journal of Agronomy and Crop Science, v. 188, n. 04, p. 225 -
234, 2002. Disponível em: <http://www3.interscience.wiley. com/journal/118955374/issue>. Acesso em: 29 jul. 2009.

OLIVEIRA, A. P. et al. Rendimento de feijão-vagem em função de doses de $\mathrm{K}_{2} \mathrm{O}$. Horticultura Brasileira, v. 25, n. 01, p. 29-33, 2007.

OLIVEIRA, A. P. et al. Rendimento produtivo e econômico do feijão-caupi em função de doses de potássio. Ciência Agrotecnologia, v. 33, n. 02, p. 629-634, 2009.

PIRES, J. L. F. et al. Avaliação de genótipos de girassol na região do Planalto Médio do Rio Grande do Sul na safra 2005/2006. Passo Fundo: Embrapa Trigo, 2007. 15 p. Disponível em: $\quad<$ http://www.cnpt.embrapa.br/biblio/bp/p_bp49.htm>. Acesso em: 20 de out. 2009.

PORTO, W. S; CARVALHO, C. G. P. de; PINTO, R. J. B. Adaptabilidade e estabilidade como critérios para a seleção de genótipos de girassol. Pesquisa Agropecuária Brasileira, v. 42, n. 04, p. 491-499, abr. 2007

PORTO, W. S. et al. Evaluation of sunflower cultivars for central Brazil. Scientia Agraria, v. 65, n. 02, p. 139-144, 2008.

RAIJ, B. van. Fertilidade do solo e adubação. Piracicaba: Ceres; Potafos, 1991. 343p.

SFREDO, G. J; CAMPO, R. J.; SARRUGE, J. R. Girassol: nutrição mineral e adubação. Londrina: Embrapa-CNPSo, 1984. 36 p. (Embrapa-CNPSo. Circular técnica, 8).

SMIDERLE, O. J.; MOURÃO JR., M.; GIANLUPPI, D. Avaliação de cultivares de girassol em savana de Roraima. Acta Amazônica, v. 35, n. 03, p. 331-336, 2005.

UCHÔA, S. C. P et al. Resposta de seis variedades de cana-deaçúcar a doses de potássio em ecossistema de cerrado de Roraima. Revista Ciência Agronomica, v. 40, n. 04, p. 505-513, 2009.

VIANA, T. V. A. et al. Diferentes doses de potássio, na forma de nitrato de potássio, aplicadas via fertirrigação no mamão formosa. Revista Ciência Agronômica, v. 39, n. 01, p. 34-38, 2008.

VILLALBA, E. O. Recomendação de nitrogênio, fósforo e potássio para girassol sob sistema de plantio direto no Paraguai/ 2008. 82f. (Dissertação de Mestrado) Mestrado em Ciências do Solo - Universidade Federal de Santa Maria, Santa Maria-RS.

VILELA, L.; SOUSA, D. M. G. e SILVA, J. E. Adubação potássica. In: SOUSA, D. M. G. e LOBATO, E., Eds. Cerrado: correção do solo e adubação. 2.ed. Brasília, Embrapa, 2004. p.169-183. 